\title{
Evaluation of Focal Cortical Dysplasia and Mixed Neuronal and Glial Tumors in Pediatric Epilepsy Patients Using ${ }^{18}$ F-FDG and ${ }^{11} \mathrm{C}$-Methionine PET
}

Ji Hoon Phi ${ }^{1,2}$, Jin Chul Paeng ${ }^{3}$, Hyo Sang Lee ${ }^{3}$, Kyu-Chang Wang ${ }^{1,2}$, Byung-Kyu Cho ${ }^{1,2}$, Ji-Yeoun Lee ${ }^{1,2}$, Sung-Hye Park ${ }^{4}$, Joongyub Lee ${ }^{5}$, Dong Soo Lee ${ }^{3}$, and Seung-Ki Kim ${ }^{1,2}$

${ }^{l}$ Division of Pediatric Neurosurgery, Seoul National University Children's Hospital, Seoul National University College of Medicine, Seoul, Korea; ${ }^{2}$ Pediatric Clinical Neuroscience Center, Seoul National University Children's Hospital, Seoul, Korea; ${ }^{3}$ Department of Nuclear Medicine, Seoul National University College of Medicine, Seoul, Korea; ${ }^{4}$ Department of Pathology, Seoul National University College of Medicine, Seoul, Korea; and ${ }^{5}$ Medical Research Collaborating Center, Seoul National University Hospital, Seoul, Korea

Focal cortical dysplasia (FCD) and mixed neuronal and glial tumors share many clinical characteristics; therefore, the presurgical differential diagnosis of these diseases using MRI is difficult in some cases. The aim of this study was to determine whether ${ }^{11} \mathrm{C}$ methionine PET, compared with ${ }^{18}$ F-FDG PET, was useful for the evaluation of these diseases. Methods: The clinical and imaging data of 30 pediatric lesional epilepsy patients pathologically diagnosed with FCD, dysembryoplastic neuroepithelial tumor (DNT), or ganglioglioma were reviewed. Eleven patients had FCD, 8 patients had a DNT, and 11 patients had a ganglioglioma. ${ }^{18} \mathrm{~F}-\mathrm{FDG}$ and ${ }^{11} \mathrm{C}$-methinine PET scans were obtained from 25 patients and 15 patients, respectively. Visual grading analysis and quantitative assessment of ${ }^{18} \mathrm{~F}-\mathrm{FDG}$ and ${ }^{11} \mathrm{C}$-methionine PET, represented as a lesion-to-gray matter ratio (LGR), were performed. Results: In the visual grading analysis, both ${ }^{18} \mathrm{~F}-\mathrm{FDG}$ PET and ${ }^{11} \mathrm{C}$-methionine PET detected a significant difference among the 3 disease groups $(P=0.033$ and $P=0.016$, respectively), but discrimination of FCD from mixed neuronal and glial tumors was possible only with ${ }^{11} \mathrm{C}$-methionine PET. The mean LGR of ${ }^{18} \mathrm{~F}-\mathrm{FDG}$ PET was $0.502 \pm 0.119$ for FCD, $0.631 \pm$ 0.107 for DNTs, and $0.620 \pm 0.196$ for gangliogliomas; there was no significant difference in LGR among the groups $(P=$ 0.111). However, the mean LGR of ${ }^{11} \mathrm{C}$-methionine PET was $1.078 \pm 0.182$ for FCD, $1.564 \pm 0.368$ for DNT, and $2.114 \pm$ 0.723 for gangliogliomas; there was a significant difference in LGR among the groups $(P=0.014)$. Post hoc analysis revealed that the LGR of FCD was significantly different from that of DNTs and gangliogliomas. The mean LGR value of DNTs fell between those of FCD and gangliogliomas. Conclusion: Although ${ }^{18} \mathrm{~F}-$ FDG plays a major role in the preoperative work-up of epilepsy surgery patients, it appears from this study that ${ }^{18} \mathrm{~F}-\mathrm{FDG}$ does

Received Sep. 20, 2009; revision accepted Feb. 12, 2010.

For correspondence or reprints contact either of the following: SeungKi Kim, Division of Pediatric Neurosurgery, Seoul National University Children's Hospital, 101 Daehangno, Jongno-gu 110-744, Seoul, Korea. E-mail: nsthomas@snu.ac.kr

Jin Chul Paeng, Department of Nuclear Medicine, Seoul National University College of Medicine, 101 Daehangno, Jongno-gu 110-744, Seoul, Korea.

E-mail: paengjc@snu.ac.kr

COPYRIGHT () 2010 by the Society of Nuclear Medicine, Inc. not contribute to the differential diagnosis and that another tracer such as ${ }^{11} \mathrm{C}$-methinine is required. ${ }^{11} \mathrm{C}$-methinine $\mathrm{PET}$ results correlated well with the pathologic spectrum in pediatric lesional epilepsy patients.

Key Words: methionine; PET; focal cortical dysplasia; dysembryoplastic neuroepithelial tumor; ganglioglioma

J Nucl Med 2010; 51:728-734

DOI: 10.2967/jnumed.109.070920

\section{Any lesions involving the brain cortex can cause} epileptic seizures. Malformation of cortical development is a broad term for a variety of developmental cortical anomalies frequently associated with epilepsy (1). Focal cortical dysplasia (FCD) is the major type of malformation of cortical development and represents a large proportion of the pathologic diagnosis in pediatric epilepsy patients (2). Because they usually appear as a discrete lesion on MRI, many FCDs, especially of high pathologic grades, can be diagnosed preoperatively using high-resolution MRI (3).

Low-grade brain tumors are another important cause of epilepsy in children and adolescents. Mixed neuronal and glial tumors (MNGTs), such as dysembryoplastic neuroepithelial tumors (DNTs) and gangliogliomas, are the most common brain tumors encountered in epilepsy surgery series (4). Although FCD and MNGTs are obviously different from each other in their pathologic characteristics, the clinical and imaging features can be similar in some cases, especially in cases of masslike FCD (5). Both diseases are diagnosed predominantly in children and adolescents and are associated with intractable epilepsy. The temporal lobe is the most frequently affected site in both diseases, which involve the brain cortex and adjacent 
subcortical regions. Although ganglioglioma typically shows contrast enhancement on MRI-a sign indicative of a brain tumor-the same tumor frequently shows no enhancement when situated in the mesial temporal lobe, making differential diagnosis using MRI complicated.

Nonetheless, preoperative differential diagnosis of FCD and MNGTs is important clinically. First, although many controversies exist regarding this subject, the treatment policy differs between these diseases. In the case of FCD, wide cortical resection over the MRI-delineated lesion using invasive electroencephalography is frequently recommended for adequate seizure control, because the histologic boundaries of FCD are not clear in many cases (6). In contrast, recent studies on tumor-associated epilepsy emphasize that total resection of the tumor is sufficient for seizure control in many patients $(7,8)$. Second, the outcome and prognosis after surgery vary significantly between these diseases. The seizure-free rates after surgery are reportedly around $70 \%-80 \%$ for tumor-associated epilepsy $(4,8)$, whereas the seizure-free rates after surgery for FCD, for all surgical techniques, fall around 40\%-50\% $(2,9)$.

Although ${ }^{18} \mathrm{~F}-\mathrm{FDG}$ PET has been extensively applied to epilepsy surgery, this technique has been focused on the metabolic suppression around the epileptogenic zone, rather than on the differential diagnosis of each lesion. ${ }^{18} \mathrm{~F}-\mathrm{FDG}$ PET is useful for the detection of high-grade malignant brain tumors but is less effective in the diagnosis of low-grade tumors (10). In contrast, ${ }^{11} \mathrm{C}$-methinine PET, which visualizes amino acid metabolism, may be a more effective method for the differential diagnosis of tumorous and nontumorous conditions, because it is both sensitive and specific for the detection of brain tumors (11-13). To date, however, the usefulness of ${ }^{11} \mathrm{C}$-methinine PET in epilepsy surgery has not received much attention.

In this study, the findings of ${ }^{18} \mathrm{~F}-\mathrm{FDG}$ and ${ }^{11} \mathrm{C}$-methinine PET studies in pediatric epilepsy patients who were pathologically diagnosed with FCD or MNGTs were compared, and the effectiveness of ${ }^{11} \mathrm{C}$-methionine PET in pediatric epilepsy surgery was investigated.

\section{MATERIALS AND METHODS}

\section{Patients}

Patients who underwent epilepsy surgery and were finally diagnosed as having FCD, DNT, or ganglioglioma-according to the operation database of the Division of Pediatric Neurosurgery of the Seoul National University Children's Hospital-were reviewed retrospectively. For FCD, patients with normal imaging, subtle gyral thickening, and hemimegalencephaly were excluded because a brain tumor cannot be suspected as the pathologic diagnosis in such cases. Only patients with a masslike lesion were included. On preoperative MRI, the lesions showed low signal intensity in T1-weighted images and high signal intensity in T2weighted images. Among them, we selected patients who underwent either preoperative ${ }^{18} \mathrm{~F}$-FDG PET or ${ }^{11} \mathrm{C}$-methinine PET. If a patient underwent repeated operations or PET scans, only the initial operation and PET scan were included in the analysis.
Thirty pediatric patients (13 men and 17 women) were eligible for this study, and the median age at surgery was $10 \mathrm{y}$ (range, $11 \mathrm{mo}$ to $17 \mathrm{y}$ ). All patients presented with epileptic seizures, and the median duration of epilepsy was $2 \mathrm{y}$ (range, 1 mo to $10 \mathrm{y}$ ) at the time of surgery. All patients had a focal masslike lesion on preoperative MRI. The lesions were located in the mesial temporal lobe in 15 patients, frontal lobe in 5 patients, lateral temporal lobe in 4 patients, occipital lobe in 3 patients, parietal lobe in 2 patients, and temporoparietal lobe in 1 patient. ${ }^{18}$ F-FDG PET scans were obtained for most of the patients as part of our presurgical evaluations for epilepsy. In cases for which a tumorous condition, such as a DNT or ganglioglioma, was highly suspected, ${ }^{18}$ F-FDG PET was combined with or replaced by ${ }^{11} \mathrm{C}$-methinine PET. ${ }^{18} \mathrm{~F}-\mathrm{FDG}$ PET was performed in 25 patients, and ${ }^{11} \mathrm{C}$ methinine PET was performed in 15 patients. All patients underwent lesionectomy with or without extended cortisectomy.

Pathologic examinations revealed FCD in 11 patients (type 1a, 3 patients; type 1b, 2 patients; type $2 \mathrm{a}, 2$ patients; and type $2 \mathrm{~b}$, 4 patients, according to the classification of Palmini et al. (14)), DNT in 8 patients, and ganglioglioma in 11 patients. Clinical information on the patients is summarized in Table 1 .

\section{${ }^{18} \mathrm{~F}-\mathrm{FDG}$ and ${ }^{11} \mathrm{C}-$ Methionine PET}

${ }^{18} \mathrm{~F}-\mathrm{FDG}$ PET was performed at a median of $5 \mathrm{~d}$ (range, $1 \mathrm{~d}$ to $32 \mathrm{mo}$ ) before surgery, and ${ }^{11} \mathrm{C}$-methionine PET was performed at a median of $6 \mathrm{~d}$ (range, $1 \mathrm{~d}$ to $6 \mathrm{mo}$ ) before surgery. In the 10 cases in which both scans were obtained for the same patient, the median interval between the scans was $1 \mathrm{~d}$ (range, 0-5 d). For PET scans, patients fasted for at least $6 \mathrm{~h}$, and $7.4 \mathrm{MBq}$ of ${ }^{18} \mathrm{~F}-\mathrm{FDG}$ per kilogram or $5.55 \mathrm{MBq}$ of ${ }^{11} \mathrm{C}$-methionine per kilogram were injected into each patient. Transmission scans were obtained using ${ }^{6}{ }^{68} \mathrm{Ge}$ rod source or a CT scanner, with the patient resting supine; the emission scan was started 40 min after injection in the case of ${ }^{18} \mathrm{~F}-\mathrm{FDG}$ and $10 \mathrm{~min}$ after injection in the case of ${ }^{11} \mathrm{C}$-methionine. Scan images were acquired for 20 min using a dedicated PET scanner (ECAT EXACT 47; Siemens) or PET/CT scanners (Gemini [Philips] or Biograph 40 [Siemens]).

\section{Image Analysis of PET Results}

The overall quality of the PET images was initially assessed by 2 nuclear medicine physicians. For visual grading analyses, MR images were reviewed simultaneously with the PET images. The uptake of ${ }^{18} \mathrm{~F}$-FDG or ${ }^{11} \mathrm{C}$-methionine was assessed on the PET image slice, which was matched with the MR image slice of the lesion, using a 7-grade system. In the grading system, a lesion that showed uptake of no significant difference from that of the contralateral area was defined as a normometabolic lesion. Lesions of increased or decreased uptake were classified as mild, moderate, and marked hyper- or hypometabolic lesions. All gradings were performed by agreement of 2 nuclear medicine physicians who were unaware of the pathologic results.

For quantitative assessment, a circular region of interest (ROI) was drawn for the lesion designated on MRI, with the minimal size including the whole lesion. The maximal count of the lesion $\left(\mathrm{L}_{\max }\right)$ was measured in the ROI of a lesion. Subsequently, 3 circular ROIs of a predetermined size were drawn on the gray matter of the contralateral frontal, parietal, and temporal lobes, which were used as reference sites (Supplemental Fig. 1; supplemental materials are available online only at http://jnm.snmjournals. org). The mean value of the 3 ROIs was used as the mean contralateral gray matter uptake $\left(\mathrm{G}_{\text {mean }}\right)$. The lesion-to-gray matter 


\begin{tabular}{|c|c|c|c|c|c|}
\hline $\begin{array}{c}\text { Patient } \\
\text { no. }\end{array}$ & Sex & $\begin{array}{l}\text { Age at } \\
\text { surgery }\end{array}$ & $\begin{array}{c}\text { Duration of } \\
\text { epilepsy }\end{array}$ & Location & $\begin{array}{l}\text { Pathologic } \\
\text { diagnosis }\end{array}$ \\
\hline 1 & $\mathrm{~F}$ & $10 y$ & $10 y$ & Frontal & FCD la \\
\hline 2 & M & $6 y$ & $1 y$ & $\begin{array}{l}\text { Mesial } \\
\text { temporal }\end{array}$ & FCD la \\
\hline 3 & M & $16 y$ & $4 y$ & Occipital & FCD la \\
\hline 4 & $F$ & $2 y$ & $1 \mathrm{mo}$ & $\begin{array}{l}\text { Mesial } \\
\text { temporal }\end{array}$ & FCD, Ib \\
\hline 5 & M & $8 y$ & $2 y$ & $\begin{array}{l}\text { Mesial } \\
\text { temporal }\end{array}$ & FCD, Ib \\
\hline 6 & M & $13 y$ & $6 y$ & $\begin{array}{l}\text { Mesial } \\
\text { temporal }\end{array}$ & FCD, Ila \\
\hline 7 & M & $13 y$ & $9 \mathrm{mo}$ & $\begin{array}{l}\text { Lateral } \\
\text { temporal }\end{array}$ & FCD, Ila \\
\hline 8 & $\mathrm{~F}$ & $5 y$ & $3 y$ & Frontal & FCD, Ilb \\
\hline 9 & M & $8 y$ & $4 \mathrm{~m}$ & Frontal & FCD, Ilb \\
\hline 10 & M & $4 y$ & $3 y$ & $\begin{array}{l}\text { Lateral } \\
\text { temporal- } \\
\text { parietal }\end{array}$ & FCD, Ilb \\
\hline 11 & $F$ & $4 y$ & $1 \mathrm{y}$ & Parietal & FCD, Ilb \\
\hline 12 & M & $15 y$ & $2 y$ & Frontal & DNT \\
\hline 13 & $\mathrm{~F}$ & $12 y$ & $2 y$ & $\begin{array}{l}\text { Mesial } \\
\text { temporal }\end{array}$ & DNT \\
\hline 14 & $\mathrm{~F}$ & $11 \mathrm{mo}$ & $2 \mathrm{mo}$ & $\begin{array}{l}\text { Mesial } \\
\text { temporal }\end{array}$ & DNT \\
\hline 15 & $\mathrm{~F}$ & $11 \mathrm{y}$ & $5 \mathrm{mo}$ & $\begin{array}{l}\text { Mesial } \\
\text { temporal }\end{array}$ & DNT \\
\hline 16 & M & $9 y$ & $6 y$ & $\begin{array}{l}\text { Mesial } \\
\text { temporal }\end{array}$ & DNT \\
\hline 17 & $\mathrm{~F}$ & $13 y$ & $2 y$ & $\begin{array}{l}\text { Lateral } \\
\text { temporal }\end{array}$ & DNT \\
\hline 18 & $\mathrm{~F}$ & $5 y$ & $3 y$ & Occipital & DNT \\
\hline 19 & M & $17 y$ & $8 y$ & Parietal & DNT \\
\hline 20 & $\mathrm{~F}$ & $9 y$ & $7 \mathrm{mo}$ & Frontal & Ganglioglioma \\
\hline 21 & $\mathrm{~F}$ & $10 y$ & $7 y$ & $\begin{array}{l}\text { Mesial } \\
\text { temporal }\end{array}$ & Ganglioglioma \\
\hline 22 & $\mathrm{~F}$ & $10 y$ & $9 y$ & $\begin{array}{l}\text { Mesial } \\
\text { temporal }\end{array}$ & Ganglioglioma \\
\hline 23 & M & $1 y$ & $1 y$ & $\begin{array}{l}\text { Mesial } \\
\text { temporal }\end{array}$ & Ganglioglioma \\
\hline 24 & $F$ & $1 \mathrm{y}$ & $2 \mathrm{mo}$ & $\begin{array}{l}\text { Mesial } \\
\text { temporal }\end{array}$ & Ganglioglioma \\
\hline 25 & $\mathrm{~F}$ & $11 y$ & $2 \mathrm{mo}$ & $\begin{array}{l}\text { Mesial } \\
\text { temporal }\end{array}$ & Ganglioglioma \\
\hline 26 & $F$ & $11 y$ & $7 y$ & $\begin{array}{l}\text { Mesial } \\
\text { temporal }\end{array}$ & Ganglioglioma \\
\hline 27 & $F$ & $6 y$ & $5 y$ & $\begin{array}{l}\text { Mesial } \\
\text { temporal }\end{array}$ & Ganglioglioma \\
\hline 28 & M & $15 y$ & $1 \mathrm{mo}$ & $\begin{array}{l}\text { Lateral } \\
\text { temporal }\end{array}$ & Ganglioglioma \\
\hline 29 & M & $10 y$ & $5 \mathrm{mo}$ & $\begin{array}{l}\text { Lateral } \\
\text { temporal }\end{array}$ & Ganglioglioma \\
\hline 30 & $\mathrm{~F}$ & $12 y$ & $3 \mathrm{mo}$ & Occipital & Ganglioglioma \\
\hline
\end{tabular}

ratio (LGR) was defined as $\mathrm{L}_{\max } / \mathrm{G}_{\text {mean }}$ and represented quantitative tumor uptake.

\section{Statistical Analyses}

The patients were classified into 3 pathologic diagnosis groups: FCD, DNT, and ganglioglioma. The Kruskal-Wallis test was performed to compare the visual grading among the 3 groups and to compare the distribution of LGR among the groups. We also performed a post hoc analysis in cases for which the Kruskal-Wallis test yielded a significant result. All $P$ values were tested as 2-sided, and significance was set at a $P$ value less than 0.05. SPSS (version 17.0; SPSS Inc.) and MedCalc (version 11.0; MedCalc Software) software were used for the statistical analyses.

\section{RESULTS}

Among the 11 patients with FCD, preoperative ${ }^{18} \mathrm{~F}-\mathrm{FDG}$ PET was performed in 9 patients and ${ }^{11} \mathrm{C}$-methinine PET was performed in 4 patients (Fig. 1). Among the 8 patients with DNT, ${ }^{18} \mathrm{~F}$-FDG PET was performed in 5 patients and ${ }^{11} \mathrm{C}$-methinine PET was performed in 5 patients (Fig. 2). Among the 11 patients with ganglioglioma, all patients underwent ${ }^{18} \mathrm{~F}$-FDG PET and 6 patients underwent ${ }^{11} \mathrm{C}$ methinine PET (Fig. 3).

In visual grading analyses, ${ }^{18}$ F-FDG PET showed hypometabolic lesions predominantly, regardless of the type of pathologic entity. Only 2 patients (one with FCD and the other with ganglioglioma) showed mild and moderate hypermetabolism, respectively, in their lesions (Table 2). There was a significant difference in the visual grading between the 3 groups $(P=0.033)$. Post hoc analysis showed that the visual grades of FCD were significantly different from those of gangliogliomas but that there was no difference in the grades of DNTs from those of FCD or
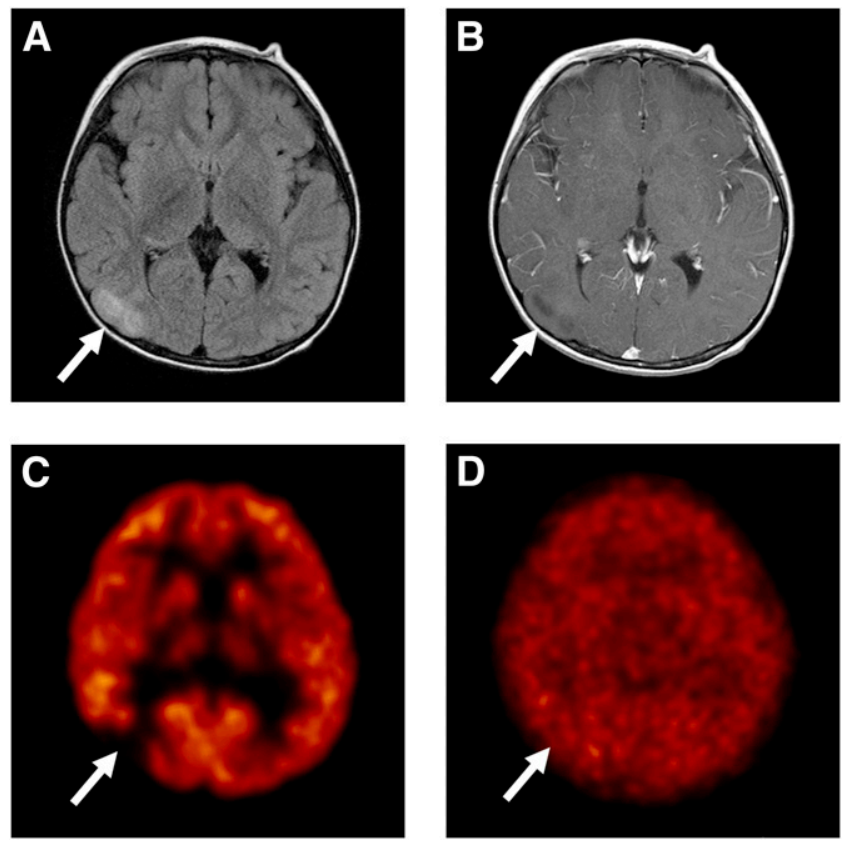

FIGURE 1. PET images of 4-y-old girl with 1-y history of epilepsy (patient 11) showed masslike lesion (arrows) with high signal intensity in right parietal lobe on fluid-attenuated inversion recovery MR image (A). No contrast enhancement was observed on gadolinium-enhanced T1-weighted MR image (B). Lesion was markedly hypometabolic on ${ }^{18} \mathrm{~F}-\mathrm{FDG}$ PET (C) and normometabolic on ${ }^{11} \mathrm{C}$-methinine PET (D). After surgery, lesion was identified as FCD, of type $2 \mathrm{~b}$. 

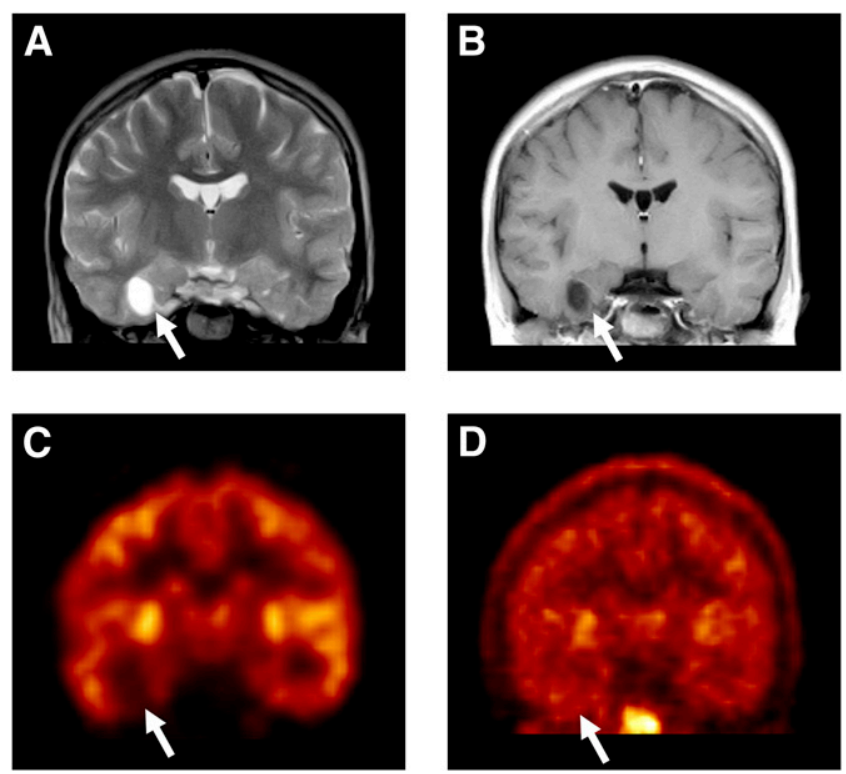

FIGURE 2. PET images of 13-y-old girl with 2-y history of epilepsy (patient 17) showed masslike lesion (arrows) with high signal intensity in right fusiform gyrus on T2-weighted MR image (A). Lesion had no contrast enhancement on gadolinium-enhanced T1-weighted MR image (B). Lesion was moderately hypometabolic on ${ }^{18} \mathrm{~F}-\mathrm{FDG}$ PET (C) and mildly hypermetabolic on ${ }^{11} \mathrm{C}$-methinine PET (D). After surgery, lesion was identified as DNT.

gangliogliomas. Therefore, discrimination of FCD from MNGTs was not possible by visual grading of ${ }^{18} \mathrm{~F}-\mathrm{FDG}$ PET data.

In contrast, FCD and MNGTs exhibited different results on ${ }^{11} \mathrm{C}$-methinine PET. None of the FCD patients showed hypermetabolism in their lesions, and none of the DNT and ganglioglioma patients showed hypometabolism in their lesions (Table 3). The grades of ${ }^{11} \mathrm{C}$-methionine uptake were significantly different among the 3 groups $(P=$ 0.016). Post hoc analysis revealed that the visual grades of FCD were significantly different from those of DNTs and gangliogliomas.

The quantitative assessment of ${ }^{18} \mathrm{~F}$-FDG and ${ }^{11} \mathrm{C}$-methionine PET, represented by LGR, revealed that the mean LGR of ${ }^{18} \mathrm{~F}-\mathrm{FDG}$ uptake was $0.502 \pm 0.119$ for $\mathrm{FCD}$, $0.631 \pm 0.107$ for DNT, and $0.620 \pm 0.196$ for ganglioglioma; there was no significant difference in LGR among the groups $(P=0.111)$ (Fig. 4). However, the mean LGR of ${ }^{11} \mathrm{C}$-methionine uptake was $1.078 \pm 0.182$ for $\mathrm{FCD}$, $1.564 \pm 0.368$ for DNT, and $2.114 \pm 0.723$ for gangliogliomas; there was a significant difference in LGR among the groups $(P=0.014)$. Post hoc analysis revealed that the LGR of the FCD patients was significantly different from that of the DNT and ganglioglioma patients. Although no significant difference between the LGR of DNT and ganglioglioma was observed, the mean LGR value of DNT lay between that of FCD and gangliogliomas.

\section{DISCUSSION}

Preoperative imaging diagnosis of pathologic characteristics is important in epilepsy surgery. Most surgical decisions including the selection of surgical candidates, determination of when and how to operate, and outcome expectation depend heavily on the pathologic diagnosis. Although MRI has revolutionized the field of preoperative diagnosis, some lesions resist differentiation from other entities, even using high-resolution MRI. FCD and MNGTs are typical examples that confuse clinicians.

Since Taylor's classic description of the imaging and pathologic features of FCD (15), this disease has been well characterized as a distinct clinicopathologic entity. The imaging features of FCD are quite diverse, ranging from the absence of abnormality or subtle gyral thickening to a tumorlike lesion (5). Although FCD usually lacks contrast enhancement on MRI, there are some exceptions $(16,17)$. Many DNTs show minimal or no contrast enhancement on MRI. Gangliogliomas usually show contrast enhancement, but gangliogliomas located in the mesial temporal lobe tend to show no contrast enhancement. Therefore, it is often difficult to make a preoperative diagnosis for a masslike lesion in epilepsy patients (16).

${ }^{18} \mathrm{~F}-\mathrm{FDG}$ PET is an effective diagnostic imaging method for epilepsy and brain tumors. In addition, FCD exhibits metabolic suppression during the interictal period and focal or lobar hypometabolism is demonstrated on ${ }^{18} \mathrm{~F}$-FDG PET
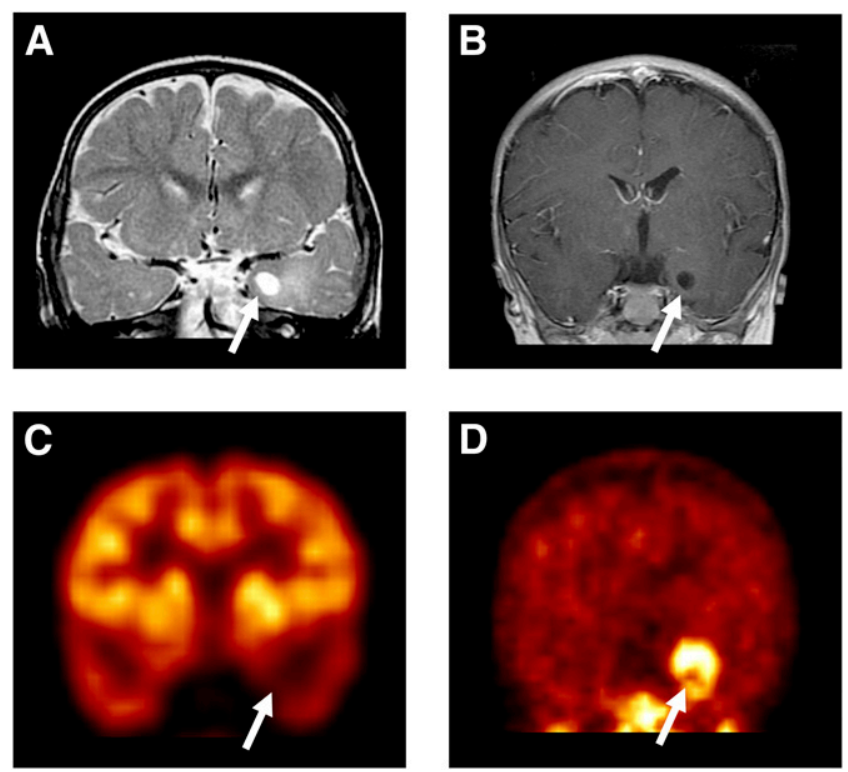

FIGURE 3. PET images of 1-y-old girl with 2-mo history of epilepsy (patient 24) showed masslike lesion (arrows) with high signal intensity in left mesial temporal lobe on T2weighted MR image (A). Lesion had no contrast enhancement on gadolinium-enhanced T1-weighted MR image (B). Lesion was moderately hypometabolic on ${ }^{18} \mathrm{~F}$-FDG PET (C) and markedly hypermetabolic on ${ }^{11} \mathrm{C}$-methinine PET (D). It was identified as ganglioglioma on pathologic examination. 
TABLE 2. Visual Grading Analyses of Lesions on

18F-FDG PET

\begin{tabular}{|lccc}
\hline & \multicolumn{3}{c}{ Pathologic group } \\
\cline { 2 - 4 } \multicolumn{1}{c}{ Visual grade } & 0 & 0 & 0 \\
\hline Markedly hypermetabolic & DNT & Ganglioglioma \\
\hline Moderately hypermetabolic & 0 & 0 & 1 \\
\hline Mildly hypermetabolic & 1 & 0 & 0 \\
\hline Normometabolic & 0 & 0 & 0 \\
\hline Mildly hypometabolic & 0 & 1 & 5 \\
\hline Moderately hypometabolic & 4 & 4 & 5 \\
\hline Markedly hypometabolic & 4 & 0 & 0 \\
\hline Total (patients) & 9 & 5 & 11 \\
\hline
\end{tabular}

(18). However, many low-grade brain tumors also show hypo- or normometabolism on ${ }^{18} \mathrm{~F}$-FDG PET. Therefore, if a masslike lesion is present on MRI, neither MRI nor ${ }^{18} \mathrm{~F}-$ FDG PET can reliably distinguish FCD from brain tumors, although they are the most commonly used diagnostic imaging methods for the presurgical evaluation of epilepsy patients.

MNGTs are a heterogeneous group of brain tumors that have both neuronal and glial components (19). DNT and ganglioglioma are the most common entities in this group. MNGTs are true neoplasms that grow and sometimes undergo malignant progression. However, some authors include them in the classification of malformation of cortical development, because the tumors retain the histologic features of cortical maldevelopment (20). Furthermore, DNTs and gangliogliomas are frequently combined with FCD, which suggests the presence of a common pathogenetic mechanism for these diseases.

Presurgical imaging diagnosis of FCD and MNGTs is one of the clinically crucial problems in pediatric epilepsy surgery. The extent of FCD is considered wider than that of the lesion observed on MRI. Currently, however, no imaging modality exists that can accurately define the full extent of FCD, resection of which is indispensable for seizure control. Therefore, surgery for FCD relies heavily on electrophysiologic studies, such as invasive electroencephalography monitoring, and the prognosis of patients with FCD remains gloomy because, at best, only half of the patients receiving an extensive cortical resection become seizure-free (2). In contrast, MNGTs usually have distinct boundaries, and complete resection of the tumor is achieved in many patients. Because MNGTs are frequently associated with FCD in the adjacent cortex, it remains controversial whether extensive invasive electroencephalography monitoring and cortical resection are required for patients with these tumors (2123). Nonetheless, recent studies on tumor-related chronic epilepsy emphasize that complete removal of the tumor itself is the most important prognostic factor for seizure control $(7,8,23)$. The prognosis of tumor-related epilepsy is excellent, with seizure-free rates approaching $80 \%(4,8)$. Therefore, surgical strategies and outcome expectation could be deeply influenced by the presurgical imaging diagnosis of the lesion.
TABLE 3. Visual Grading Analyses of Lesions on

${ }^{11} \mathrm{C}-$ Methinine PET

\begin{tabular}{|lccc} 
& \multicolumn{3}{c}{ Pathologic group } \\
\cline { 2 - 4 } \multicolumn{1}{c}{ Visual grade } & FCD & DNT & Ganglioglioma \\
\hline Markedly hypermetabolic & 0 & 0 & 3 \\
\hline Moderately hypermetabolic & 0 & 2 & 1 \\
\hline Mildly hypermetabolic & 0 & 3 & 1 \\
\hline Normometabolic & 2 & 0 & 1 \\
\hline Mildly hypometabolic & 2 & 0 & 0 \\
\hline Moderately hypometabolic & 0 & 0 & 0 \\
\hline Markedly hypometabolic & 0 & 0 & 0 \\
\hline Total (patients) & 4 & 5 & 6 \\
\hline
\end{tabular}

In this study, we compared ${ }^{18} \mathrm{~F}$-FDG and ${ }^{11} \mathrm{C}$-methionine PET in FCD, DNTs, and gangliogliomas. ${ }^{18} \mathrm{~F}-\mathrm{FDG}$ images represent energy metabolism of tissues, and ${ }^{11} \mathrm{C}$-methionine images represent amino acid metabolism and, consequently, the synthesis of peptides and proteins. ${ }^{18} \mathrm{~F}-\mathrm{FDG}$

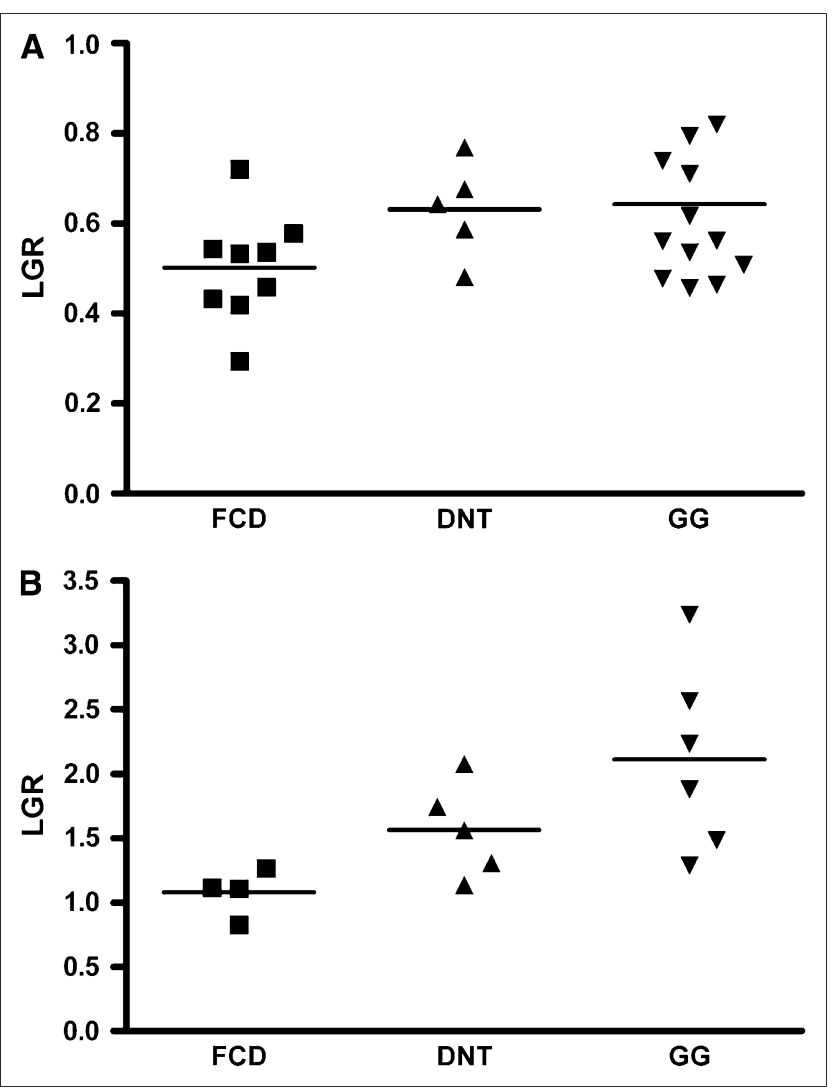

FIGURE 4. Quantitative assessment of ${ }^{18} \mathrm{~F}-\mathrm{FDG}$ and ${ }^{11} \mathrm{C}$ methionine PET according to pathologic diagnoses: FCD, DNT, and gangliogliomas (GG). Comparison of ${ }^{18} \mathrm{~F}-\mathrm{FDG}$ PET results, represented by $L G R$, revealed absence of difference among groups $(P=0.111)(\mathrm{A})$. Comparison of ${ }^{11} \mathrm{C}$ methionine PET results among the groups revealed significant difference in LGR among groups $(P=0.014)(B)$. Post hoc analysis revealed that LGR of FCD was significantly different from that of DNT and ganglioglioma. 
has a limited sensitivity in the evaluation of brain tumors because many low-grade tumors have low-energy metabolism and hardly any uptake of ${ }^{18} \mathrm{~F}-\mathrm{FDG}$. In contrast, ${ }^{11} \mathrm{C}$ methionine PET is more sensitive for brain tumors than ${ }^{18} \mathrm{~F}-$ FDG because of low background activity in the normal brain tissue. Furthermore, ${ }^{11} \mathrm{C}$-methionine is expected to be effective also in the discrimination of low-grade brain tumors from nontumorous lesions such as FCD, because peptide synthesis can be a specific biomarker for tumors, even if the energy metabolism is low. In this study, ${ }^{11} \mathrm{C}$ methionine PET revealed a significantly higher uptake in DNTs and gangliogliomas than in FCD, whereas ${ }^{18} \mathrm{~F}-\mathrm{FDG}$ PET did not reveal any differences among the groups in the quantitative analysis, as expected. These results are consistent with previous studies showing that ${ }^{11} \mathrm{C}$-methionine PET has a higher sensitivity and specificity for the diagnosis of brain tumors than does ${ }^{18}$ F-FDG PET (11-13). This result suggests that ${ }^{11} \mathrm{C}$-methionine PET is effective in the differential diagnosis of pediatric lesional epilepsy.

This study showed that the average LGR of DNTs on ${ }^{11} \mathrm{C}$-methionine PET fell between those of FCD and gangliogliomas. This finding is reminiscent of the pathologic conjecture that DNT lies between FCD and bona fide brain tumors. DNT is an extremely benign brain tumor with excellent long-term oncologic outcome, whereas gangliogliomas are associated with a more aggressive astroglial component and their oncologic prognosis is worse than that of DNT. Also noteworthy is that the individual LGR values of DNTs and gangliogliomas were distributed over a rather wide range. This may reflect the pathologic and clinical heterogeneity of DNTs and gangliogliomas. The wide histologic spectrum of DNTs remains poorly understood, and gangliogliomas exhibit diverse features, from a welldifferentiated tumor to an anaplastic variant (19). Although it has long been held that DNTs do not recur, even after incomplete resection (24), recurrence and progression of some DNTs have been reported $(8,25)$. The clinical behavior of gangliogliomas is also unpredictable, with malignant progression occurring in some patients $(26,27)$. A study including additional patients may reveal whether the distinction of DNTs from gangliogliomas and the clinical stratification of these tumors using ${ }^{11} \mathrm{C}$-methionine PET are possible.

\section{CONCLUSION}

Preoperative imaging diagnosis of FCD and MNGTs is important for the determination of treatment strategies and expectation of outcome in pediatric epilepsy. Whereas ${ }^{18} \mathrm{~F}$ FDG PET did not contribute to the differentiation of FCD and MNGTs, ${ }^{11} \mathrm{C}$-methinine PET identified a significant difference among these diseases. Specifically, DNTs and gangliogliomas showed a higher ${ }^{11} \mathrm{C}$-methinine uptake than FCD. Moreover, the average LGR of DNTs on ${ }^{11} \mathrm{C}$ methionine PET fell between that of FCD and ganglioglioma. These findings suggest that ${ }^{11} \mathrm{C}$-methinine PET results correlated well with the pathologic spectrum of pediatric lesional epilepsy.

\section{ACKNOWLEDGMENTS}

This work was supported in part by the Korea Science and Engineering Foundation (KOSEF) grant funded by the Korean government (MEST) (to Seung-Ki Kim, R01-2008000-20268-0) and by a National Research Foundation of Korea grant funded by the Korean government (to KyuChang Wang, 2009-007-6743).

\section{REFERENCES}

1. Sisodiya SM. Malformations of cortical development: burdens and insights from important causes of human epilepsy. Lancet Neurol. 2004;3:29-38.

2. Hader WJ, Mackay M, Otsubo H, et al. Cortical dysplastic lesions in children with intractable epilepsy: role of complete resection. J Neurosurg. 2004;100: $110-117$.

3. Colombo N, Tassi L, Galli C, et al. Focal cortical dysplasias: MR imaging, histopathologic, and clinical correlations in surgically treated patients with epilepsy. AJNR. 2003;24:724-733.

4. Luyken C, Blumcke I, Fimmers R, et al. The spectrum of long-term epilepsyassociated tumors: long-term seizure and tumor outcome and neurosurgical aspects. Epilepsia. 2003;44:822-830.

5. Raybaud C, Shroff M, Rutka JT, Chuang SH. Imaging surgical epilepsy in children. Childs Nerv Syst. 2006;22:786-809.

6. Krsek P, Maton B, Jayakar P, et al. Incomplete resection of focal cortical dysplasia is the main predictor of poor postsurgical outcome. Neurology. 2009; 72:217-223.

7. Zaatreh MM, Firlik KS, Spencer DD, Spencer SS. Temporal lobe tumoral epilepsy: characteristics and predictors of surgical outcome. Neurology. 2003;61: 636-641.

8. Phi JH, Kim SK, Cho BK, et al. Long-term surgical outcomes of temporal lobe epilepsy associated with low-grade brain tumors. Cancer. 2009;115: 5771-5779.

9. Kim DW, Lee SK, Chu K, et al. Predictors of surgical outcome and pathologic considerations in focal cortical dysplasia. Neurology. 2009;72:211-216.

10. Padma MV, Said S, Jacobs M, et al. Prediction of pathology and survival by FDG PET in gliomas. J Neurooncol. 2003;64:227-237.

11. Chung JK, Kim YK, Kim SK, et al. Usefulness of ${ }^{11} \mathrm{C}$-methionine PET in the evaluation of brain lesions that are hypo- or isometabolic on ${ }^{18}$ F-FDG PET. Eur J Nucl Med Mol Imaging. 2002;29:176-182.

12. Pirotte B, Goldman S, Massager N, et al. Comparison of ${ }^{18} \mathrm{~F}-\mathrm{FDG}$ and ${ }^{11} \mathrm{C}$ methionine for PET-guided stereotactic brain biopsy of gliomas. J Nucl Med. 2004;45:1293-1298.

13. Wong TZ, van der Westhuizen GJ, Coleman RE. Positron emission tomography imaging of brain tumors. Neuroimaging Clin N Am. 2002;12:615-626.

14. Palmini A, Najm I, Avanzini G, et al. Terminology and classification of the cortical dysplasias. Neurology. 2004;62:S2-S8.

15. Taylor DC, Falconer MA, Bruton CJ, Corsellis JA. Focal dysplasia of the cerebral cortex in epilepsy. J Neurol Neurosurg Psychiatry. 1971;34:369-387.

16. Bronen RA, Vives KP, Kim JH, Fulbright RK, Spencer SS, Spencer DD. Focal cortical dysplasia of Taylor, balloon cell subtype: MR differentiation from lowgrade tumors. AJNR. 1997;18:1141-1151.

17. Urbach H, Scheffler B, Heinrichsmeier $T$, et al. Focal cortical dysplasia of Taylor's balloon cell type: a clinicopathological entity with characteristic neuroimaging and histopathological features, and favorable postsurgical outcome. Epilepsia. 2002;43:33-40.

18. Goffin K, Dedeurwaerdere S, Van Laere K, Van Paesschen W. Neuronuclear assessment of patients with epilepsy. Semin Nucl Med. 2008;38:227-239.

19. Louis DN, Ohgaki H, Wiestler OD, Cavenee WK, eds. WHO Classification of Tumours of the Central Nervous System. Lyon, France: International Agency for Research on Cancer; 2007.

20. Barkovich AJ, Kuzniecky RI, Jackson GD, Guerrini R, Dobyns WB. A developmental and genetic classification for malformations of cortical development. Neurology. 2005;65:1873-1887.

21. Cataltepe O, Turanli G, Yalnizoglu D, Topcu M, Akalan N. Surgical management of temporal lobe tumor-related epilepsy in children. J Neurosurg. 2005;102: 280-287. 
22. Lombardi D, Marsh R, de Tribolet N. Low grade glioma in intractable epilepsy: lesionectomy versus epilepsy surgery. Acta Neurochir Suppl. 1997;68:70-74.

23. Giulioni M, Galassi E, Zucchelli M, Volpi L. Seizure outcome of lesionectomy in glioneuronal tumors associated with epilepsy in children. J Neurosurg. 2005;102: 288-293.

24. Daumas-Duport C, Scheithauer BW, Chodkiewicz JP, Laws ER Jr, Vedrenne C. Dysembryoplastic neuroepithelial tumor: a surgically curable tumor of young patients with intractable partial seizures: report of thirty-nine cases. Neurosurgery. 1988;23:545-556.
25. Rushing EJ, Thompson LD, Mena H. Malignant transformation of a dysembryoplastic neuroepithelial tumor after radiation and chemotherapy. Ann Diagn Pathol. 2003; 7:240-244.

26. Majores M, von Lehe M, Fassunke J, Schramm J, Becker AJ, Simon M. Tumor recurrence and malignant progression of gangliogliomas. Cancer. 2008;113: 3355-3363.

27. El Khashab M, Gargan L, Margraf L, et al. Predictors of tumor progression among children with gangliogliomas: clinical article. J Neurosurg Pediatr. 2009; 3:461-466. 